\title{
Application of Digital Image Correlation to Measurement of Packaging Material Mechanical Properties
}

\author{
Jian-Wei Zhou, ${ }^{1,2}$ Dong-Hong Liu, ${ }^{1}$ Lan-Yuan Shao, ${ }^{1}$ and Zhen-Lin Wang ${ }^{2}$ \\ ${ }^{1}$ School of Biosystems Engineering and Food Science, Zhejiang University, Hangzhou 310058, China \\ ${ }^{2}$ Ningbo Institute of Technology, Zhejiang University, Ningbo 315100, China \\ Correspondence should be addressed to Dong-Hong Liu; dhliu@zju.edu.cn
}

Received 21 April 2013; Revised 1 June 2013; Accepted 2 June 2013

Academic Editor: Jun Wang

Copyright (C) 2013 Jian-Wei Zhou et al. This is an open access article distributed under the Creative Commons Attribution License, which permits unrestricted use, distribution, and reproduction in any medium, provided the original work is properly cited.

\begin{abstract}
Among various packaging materials, papers and polymer plastics are the most common due to their light weights, low costs, and other advantages. However, their mechanical properties are difficult to measure precisely because of their softness. To overcome the difficulty, a new measure instrument prototype is proposed based on an optical method known as the digital image correlation (DIC). Experiments are designed to apply the DIC to measure mechanical properties of flexible packaging materials, including the stress-strain relationship, the Poisson ratio, the coefficient of heat expansion, the creep deformation, and the top-pressure deformation of corrugated box. In addition, the low frequency vibration of package is simulated, and the vibration frequencies are measured by DIC. Results obtained in the experiments illustrate the advantages of the DIC over traditional methods: noncontact, no reinforced effect, high precision over entire area, wide measurement range, and good measurement stability.
\end{abstract}

\section{Introduction}

Papers, polymer plastics, and some composite materials are widely used as packaging materials for various goods, such as food, medicine, clothing, toys, and chemicals. They belong to the type of flexible materials with low stiffness. The stressstrain curve of such a flexible packaging material usually has the natures of nonlinearity and viscoelasticity, and creep and stress relaxation are more obvious due to the softness.

It is commonly recognized that knowledge of mechanical properties of packaging materials is of great significance in quality testing, new product development, and process monitoring. Thus, to acquire accurate data for mechanical properties is extremely important [1]. For the flexible packaging materials, several problems have been faced when using traditional methods to measure necessary mechanical properties [2].

One problem is the distortion of measurement results caused by the additional reinforcement due to the instrument. In electrical measuring methods, extensometers or strainometers must be attached on sample surfaces. The stiffness of the extensometer or strainometer is much higher than that of the samples, resulting in significant increase of the sample's local stiffness. The effect is to add "additional reinforce" to the samples, the deformation and stress field will be aberrant, and the test results will be distorted.

Another problem is the requirement of large measurement ranges and/or good instrument stability. The deformations of flexible materials are usually large and nonlinear and may also depend on the load history. Therefore, the effective range for the deformations measured by the instruments should cover from as low as $10^{-6}$ to more than $10 \%$. Also the instruments should have excellent stability during the test, such as for creep test.

The third problem is a common one existent for quite long time. It is how to test and monitor packages real time during transportation in manufacturing and in supply chain. It is required that the results are accurate, the cost is low, and the measurement facility is simple and convenient. Existing electrical or optical measurement techniques cannot meet these requirements.

In response to these problems, we develop a new measure instrument prototype: DSMS (digital speckle measurement system), based on the digital image correlation (DIC). 


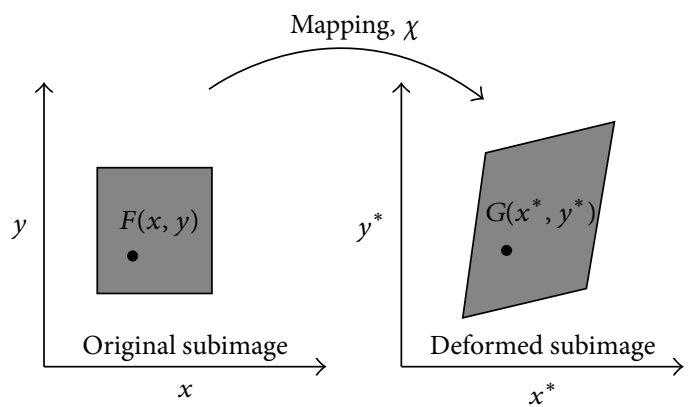

(a) Deformation mapping

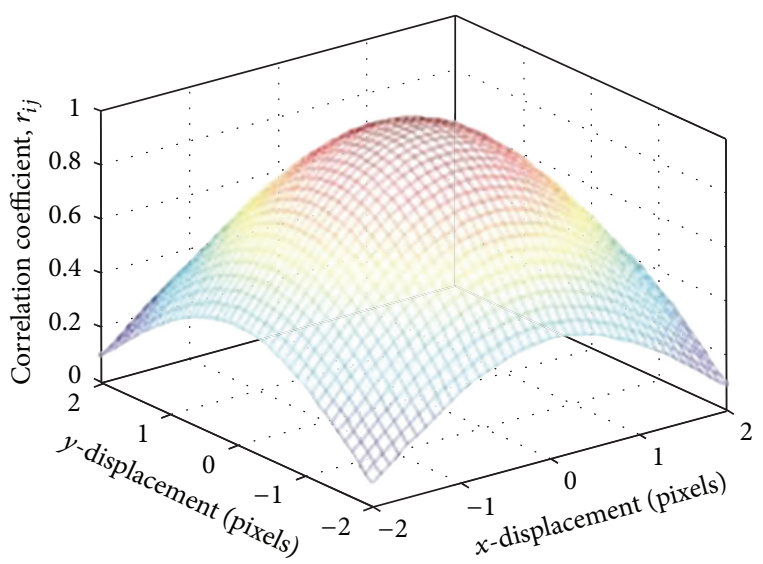

(b) Distribution of Correlation coefficient

FIgURe 1: Basic concept of DIC.

Experiments were designed and carried out to assess the accuracy of the method and to verify its applicability.

\section{Measurement Instrument Prototype}

Since DIC is the base of the proposed method, a brief review of DIC is in order. DIC is a new photo mechanics technique combined with the modern digital image processing technology. It was developed independently by Peters and Ranson [3] and Yamaguchu [4] in early eighties.

DIC is predicated on the maximization of a correlation coefficient [5] that is determined by examining pixel intensity array subsets on two or more corresponding images and extracting the deformation mapping function that relates the images (Figure 1). An iterative approach is used to maximize the $2 \mathrm{D}$ correlation coefficient by using nonlinear optimization techniques. The cross-correlation coefficient $r_{i j}$ is defined as

$$
\begin{aligned}
r_{i j}\left(u, v, \frac{\partial u}{\partial x}, \frac{\partial u}{\partial y}, \frac{\partial v}{\partial x}, \frac{\partial v}{\partial y}\right) \\
=\frac{\sum_{i} \sum_{j}\left[F\left(x_{i}, y_{j}\right)-\bar{F}\right]\left[G\left(x_{i}^{*}, y_{j}^{*}\right)-\bar{G}\right]}{\sqrt{\sum_{i} \sum_{j}\left[F\left(x_{i}, y_{j}\right)-\bar{F}\right]^{2} \sum_{i} \sum_{j}\left[G\left(x_{i}^{*}, y_{j}^{*}\right)-\bar{G}\right]^{2}}} .
\end{aligned}
$$

Here $F\left(x_{i}, y_{j}\right)$ is the pixel intensity or the gray scale value at a point $\left(x_{i}, y_{j}\right)$ in the undeformed image. $G\left(x_{i}^{*}, y_{j}^{*}\right)$ is the gray scale value at a point $\left(x_{i}^{*}, y_{j}^{*}\right)$ in the deformed image. $\bar{F}$ and $\bar{G}$ are mean values of the intensity matrices $F$ and $G$, respectively. The coordinates or grid points $\left(x_{i}, y_{j}\right)$ and $\left(x_{i}^{*}, y_{j}^{*}\right)$ are related by the deformation that occurs between the two images. If the motion is perpendicular to the optical axis of the camera, then the relation between $\left(x_{i}, y_{j}\right)$ and $\left(x_{i}^{*}, y_{j}^{*}\right)$ can be approximated by a $2 \mathrm{D}$ affine transformation such as

$$
\begin{aligned}
& x^{*}=x+u+\frac{\partial u}{\partial x} \Delta x+\frac{\partial u}{\partial y} \Delta y, \\
& y^{*}=y+v+\frac{\partial v}{\partial x} \Delta x+\frac{\partial v}{\partial y} \Delta y .
\end{aligned}
$$

Here $u$ and $v$ are translations of the center of the subimage in the $X$ and $Y$ directions, respectively. The distances from the center of the sub-image to the point $\left(x_{i}, y_{j}\right)$ are denoted by $\Delta x$ and $\Delta y$. Thus, the correlation coefficient $r_{i j}$ is a function of displacement components and displacement gradients.

Besides, the second-order shape functions can be used to depict more complicated deformation states of the deformed subset:

$$
\begin{aligned}
x^{*}= & x+u+\frac{\partial u}{\partial x} \Delta x+\frac{\partial u}{\partial y} \Delta y+\frac{1}{2} \frac{\partial^{2} u}{\partial x^{2}} \Delta x^{2} \\
& +\frac{1}{2} \frac{\partial^{2} u}{\partial y^{2}} \Delta y^{2}+\frac{1}{2} \frac{\partial^{2} u}{\partial x \partial y} \Delta x \Delta y, \\
y^{*}= & +v+\frac{\partial v}{\partial x} \Delta x+\frac{\partial v}{\partial y} \Delta y+\frac{1}{2} \frac{\partial^{2} v}{\partial x^{2}} \Delta x^{2} \\
+ & \frac{1}{2} \frac{\partial^{2} v}{\partial y^{2}} \Delta y^{2}+\frac{1}{2} \frac{\partial^{2} v}{\partial x \partial y} \Delta x \Delta y .
\end{aligned}
$$

As already mentioned, to evaluate the similarity degree between the reference and deformed subsets, a correlation criterion should be defined in advance before correlation analysis. Although different definitions of correlation criteria can be found in the literature in the past 20 years, these correlation criteria can be categorized into two groups, namely, 


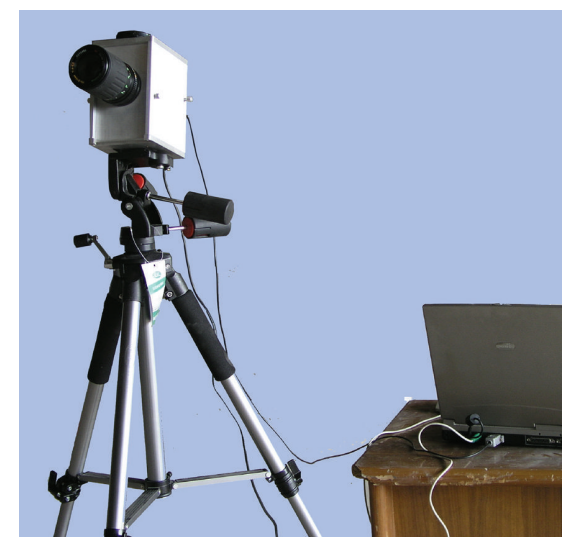

FIGURE 2: DIC measure instrument prototype: DSMS.

cross-correlation (CC) criterion or sum-squared difference (SSD) criteria [5], respectively, as

$$
\begin{gathered}
C_{\mathrm{CC}}=\sum_{i} \sum_{j}\left[F\left(x_{i}, y_{j}\right) G\left(x_{i}^{*}, y_{j}^{*}\right)\right], \\
C_{\mathrm{SSD}}=\sum_{i} \sum_{j}\left[F\left(x_{i}, y_{j}\right)-G\left(x_{i}^{*}, y_{j}^{*}\right)\right]^{2} .
\end{gathered}
$$

The DIC technique is efficient on textured objects. If the objects cannot be textured naturally, they can be marked on the surface of the object by painting (speckles). DIC is capable of not only measuring the displacement of a rigid body, but also calculating the distance, angular displacement, strain, velocity, acceleration, and even frequency $[6,7]$.

DIC has been optimized and improved in recent years [8-10]. By subpixel interpolation, the accuracy of DIC can be increased to 0.02 pixel. Moreover, the accuracy and signal-noise ratio of DIC can be improved significantly by application of several techniques, such as low-pass filter, average of samples within one time step (static measurement only).

Based on the DIC, we have developed a measure instrument prototype-DSMS, shown in Figures 2 and 3. The system includes a light source, a CCD (charge coupled device), an image processing card, and a computer as its hardware. Its software modules can perform image acquisition, correlation analysis, length calibration, and various engineering parameters calculation. It can be used to measure physical quantities, such as length, displacement, strain, velocity, acceleration, and frequency. It has the advantages of noncontact, full-field, and multipoint measurements.

To test DSMS for flexible packaging materials, we designed a series of experiments to measure the stress-strain relationship and Poisson ratio of strapping band (polypropylene, PP), the coefficient of heat expansion of polyethylene (EPE), the creep deformation of paper kraft-plastic (PE) composite, the side-pressure deformation of F-corrugated board box, and the vibration frequency of tight-wire.

\section{Experiments}

3.1. Determination of Stress-Strain Relation and Poisson Ratio. Polypropylene (PP) packing belts are widely used in tying corrugated boxes, pallets, fluffy goods, and so forth. The material has a large coefficient of elongation and elastic recovery [11]. Accurate determination of its stress-strain $(\sigma-\varepsilon)$ relationship and Poisson ratio $\mu$ is of significance to improve performance of auxiliary packaging materials and technics of bundle.

3.1.1. Materials and Methods. A PP packing belt with a dimension of $150 \mathrm{~mm} \times 8.0 \mathrm{~mm} \times 0.7 \mathrm{~mm}$ was used for testing. Four speckles were marked on the sample. An electronic universal testing machine was used to stretch the sample. Two methods were used to obtain the deformation: one is DIC using the two pairs of marked speckles, $A_{1}$ and $A_{2}$, $B_{1}$ and $B_{2}$, as shown in Figure 4 , and another was measuring the displacement of couple fixtures (CF).

Set the tensile speed at $2 \mathrm{~mm} / \mathrm{min}$ [12]. The stress $\sigma_{i}$ was calculated using

$$
\sigma_{i}=\frac{F_{i}(\mathrm{~N})}{8.0 \times 0.7\left(\mathrm{~mm}^{2}\right)} .
$$

Use DIC to measure the vertical distance $l_{A i}$ of $A_{1} A_{2}$ and horizontal distance $l_{B i}$ of $B_{1} B_{2}$ every 10 seconds until the sample is broken. At the same time record the tensile force $F_{i}$. The vertical strain $\varepsilon_{A i}$ and horizontal strain $\varepsilon_{B i}$ were calculated as

$$
\varepsilon_{A i}=\frac{l_{A i}-l_{A 0}}{l_{A 0}}, \quad \varepsilon_{B i}=\frac{l_{B i}-l_{B 0}}{l_{B 0}},
$$

where $l_{A 0}$ and $l_{B i}$ are the initial distance of $A_{1} A_{2}$ and $B_{1} B_{2}$. The Poisson ratio $\mu_{i}$ was obtained from

$$
\mu_{i}=\frac{\varepsilon_{A i}}{\varepsilon_{B i}} .
$$

In $C F$ method, the vertical strain $\varepsilon_{A i}$ was obtained from the displacement of CF and the $\sigma-\varepsilon$ curves were drawn by electronic universal testing machine.

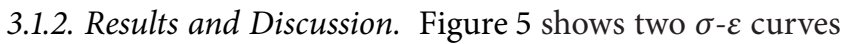
obtained by the two methods, respectively. At the same stress level, the measured strain from DIC is about 10\% larger than the CF method. This is because of slippage between the sample and the fixtures in CF method. The results acquired by DIC are obtained from gauge length directly and free from any slippage. It is noted that the extensometer and strain gauge might not be suitable in the present testing due to large extension of the PP belt. However, the DIC can always be applied to such a situation.

Figure 6 shows the variation of the Poisson ratio $\mu$ of PP packing belt with different stress level using the DIC. When the stress increases, $\mu$ decreases nonlinearly, which agrees with the nature of inelastic polymer materials. During the testing process, the deformation between two lateral speckles wss less than $0.03 \mathrm{~mm}$ for each step of load increase. Thus, more accurate results were obtained. It is not possible for conventional testing techniques. 


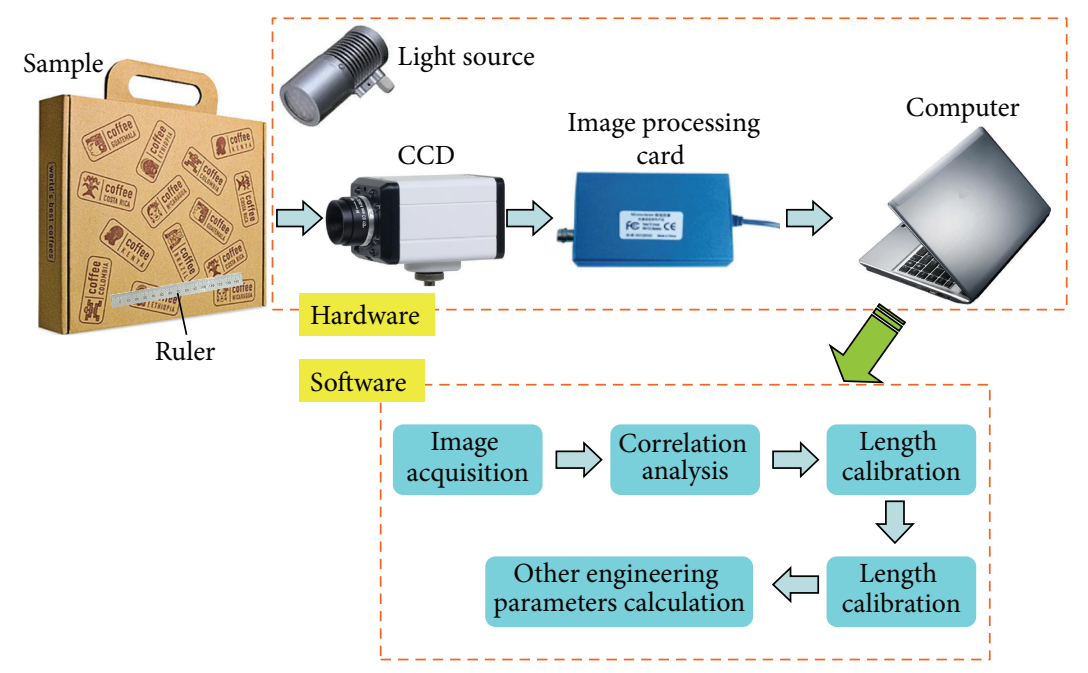

FIGURE 3: Components of DSMS.

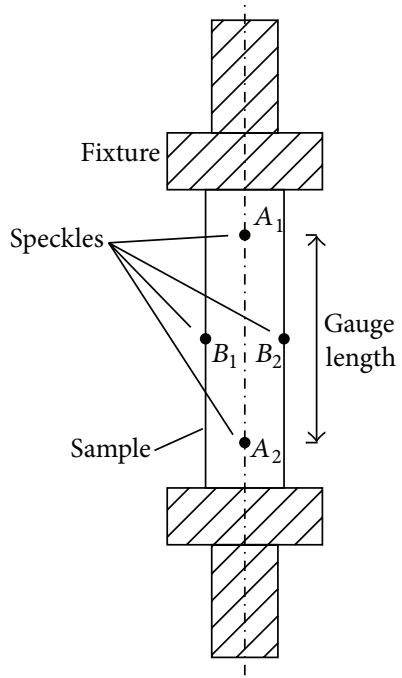

FIGURE 4: PP packing belt tensile test.

3.2. Determination of Linear Expansibility. With the popularity of freezing food and instant food, packing materials suitable for microwave and steaming have been used more and more widely. Meanwhile, packages may encounter terrible climates with violent temperature fluctuation. When designing and manufacturing this type of packaging, an important parameter is the linear expansibility $\alpha$, defined as

$$
\alpha=\frac{\Delta l}{l \cdot \Delta T}=\frac{\psi}{\Delta T}
$$

where $l$ is the gauge length, $\Delta l$ is the change in gauge length, $\Delta T$ is the temperature difference, and $\psi=\Delta l / l$ is the linear expansion rate.

Traditional method to obtain $\alpha$ is to use a dial indicator to touch the heated sample or use high-temperature strain gauges attached to the sample surfaces directly. However,

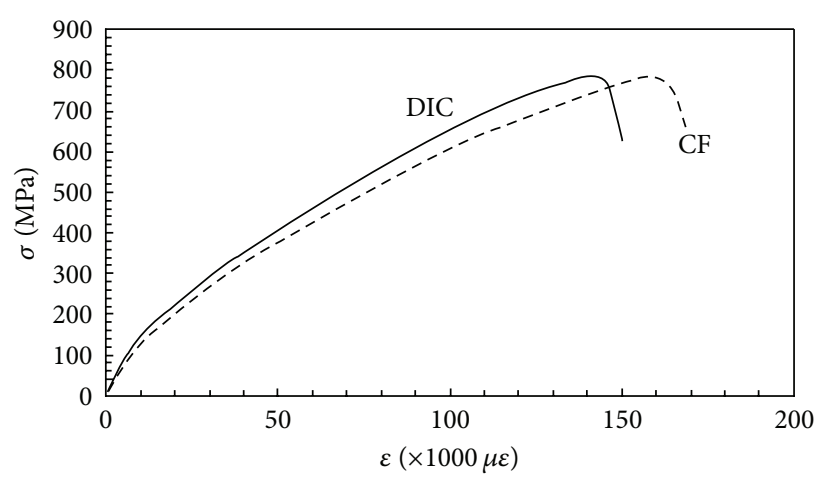

FIGURE 5: $\sigma-\varepsilon$ relations.

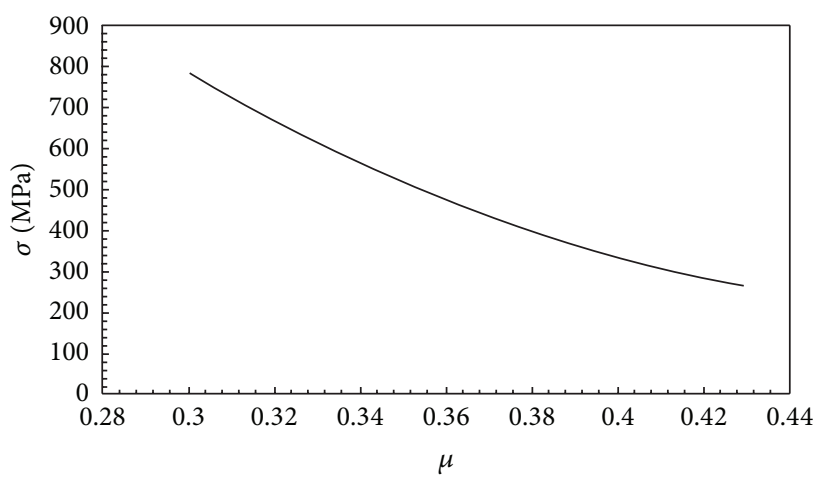

FIgURE 6: $\sigma-\mu$ relations.

these methods are inappropriate for flexible packaging material because of the additional reinforcement as mentioned in the introduction.

3.2.1. Materials and Methods. The materials used for making samples are EPE $\left(29 \mathrm{~kg} / \mathrm{m}^{3}\right)$ and PS $\left(1.05 \times 10^{3} \mathrm{~kg} / \mathrm{m}^{3}\right)$. Cut the materials into cylinders. Each cylinder has a diameter of $12 \mathrm{~mm}$ and a length of $120 \mathrm{~mm}$. Mark two points $(100 \mathrm{~mm}$ 


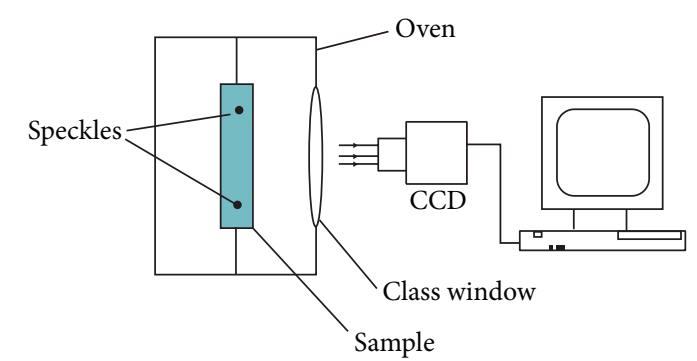

FiguRE 7: Device arrangement of linear expansibility test.

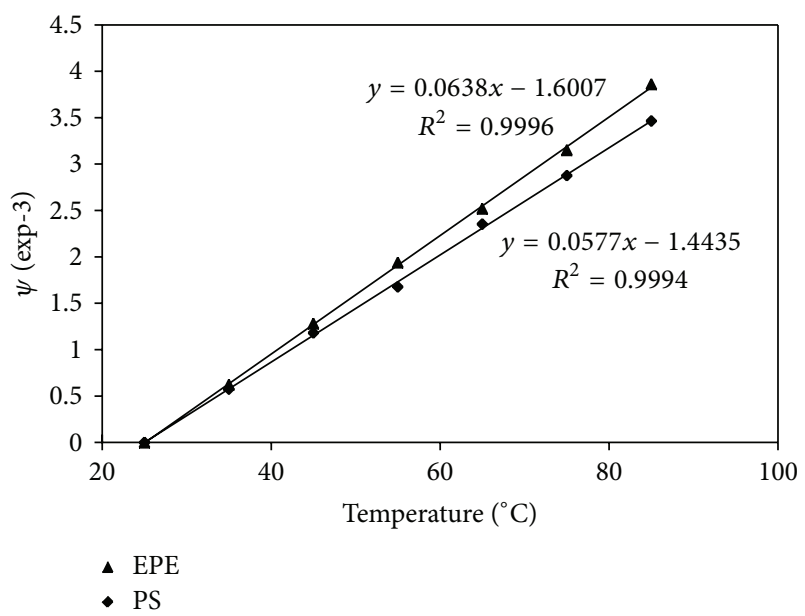

Figure 8: Linear expansion coefficients of EPE and PS.

apart) as the locations of a pair of speckles on each sample at the temperature $25^{\circ} \mathrm{C}$. Put the samples in an oven with a glass window. Place a CCD in front of the window and adjust its orientation so that its optical axis is perpendicular to the line of the two speckles, as shown in Figure 7.

After turning on the oven, its temperature was increasing from $25^{\circ} \mathrm{C}$ to $85^{\circ} \mathrm{C}$. The gauge length was measured for each increase of $10^{\circ} \mathrm{C}$ of the oven temperature by DIC. The linear expansion rate $\psi_{i}$ was calculated using

$$
\psi_{i}=\frac{l_{i}-l_{0}}{l_{0}}=\frac{\Delta l_{i}}{l_{0}},
$$

where $l_{0}$ is the initial length at $25^{\circ} \mathrm{C}$.

3.2.2. Results and Discussion. Measure $\Delta l$ and $l$ from DIC, calculate $\psi$, and draw $\psi-T$ curves, as shown in Figure 8, where $R^{2}$ is the coefficient of determination. Carry out data processing and curve fitting to obtain $\alpha$. For the two materials in the test, the average linear expansibility of EPE is $\alpha_{\mathrm{EPE}}=$ $6.38 \times 10^{-5}\left(/{ }^{\circ} \mathrm{C}\right)$ and the average linear expansibility of PS is $\alpha_{\mathrm{PS}}=5.77 \times 10^{-5}\left(/^{\circ} \mathrm{C}\right)$ between 25 and $85^{\circ} \mathrm{C}$.

In the testing, the acquisition system of the DIC was located outside of the varying temperature field and did not contact the sample directly, and the systematic error of traditional method caused by additional reinforcement was avoided. In the experiment, the change of the displacement

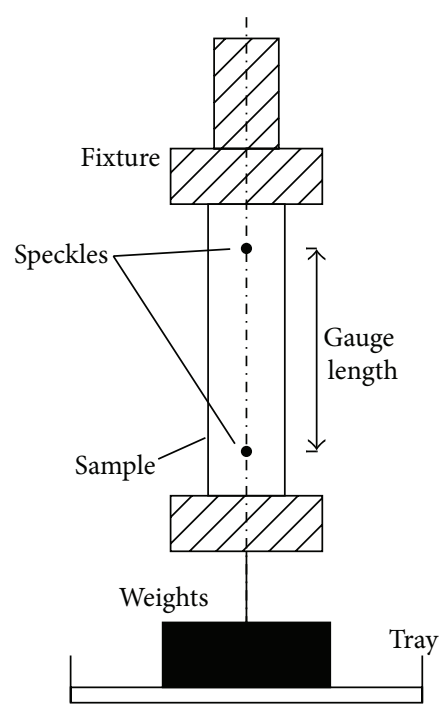

Figure 9: Creep test.

was as small as $0.005 \mathrm{~mm}$, better than dial indicator (whose precision is $0.01 \mathrm{~mm}$ ), indicating a high precision of the DIC.

3.3. Determination of Creep Law. Creep is a phenomenon of the plastic deformation of materials. For flexible viscoelastic materials, creep occurs even at a low temperature and for a relatively short time period. Thus, it needs to be addressed in design. An experiment was designed to use DSMS to evaluate the creep law of a type of paper-plastic composite material.

3.3.1. Materials and Methods. The testing sample was made of kraft-polyethylene composite, and its dimension is $150 \times$ $20 \mathrm{~mm} \times 0.2 \mathrm{~mm}$. Two speckles were marked on the sample as the gauge length, and a weight of $10 \mathrm{~kg}$ was applied, shown in Figure 9. The room temperature was maintained at $15^{\circ} \mathrm{C}$, and DIC was used to measure the distance change of the gauge length for 24 hours to obtain the creep law.

First, the initial distance of the gauge length $l_{0}$ is measured. Then, weights was put on the tray, and the gauge length $l$ had been measured at $0 \mathrm{~min}, 5 \mathrm{~min}, 10 \mathrm{~min}, 15 \mathrm{~min}, 30 \mathrm{~min}$, $1 \mathrm{~h}, 1.5 \mathrm{~h}, 2 \mathrm{~h}, 4 \mathrm{~h}, 6 \mathrm{~h}, 8 \mathrm{~h}, 10 \mathrm{~h}, 15 \mathrm{~h}, 20 \mathrm{~h}$, and $24 \mathrm{~h}$. The strain $\varepsilon_{i}$ is calculated using

$$
\varepsilon_{0}=\frac{l_{0}-l}{l}, \quad \varepsilon_{i}=\frac{l_{i}-l}{l} .
$$

3.3.2. Results and Discussion. The tensile strength is calculated as $\sigma=P / s=100 \mathrm{~N} /(20 \mathrm{~mm} \times 0.2 \mathrm{~mm})=25 \mathrm{MPa}$. Figure 10 depicts the creep curve $(\varepsilon-t)$ for 24 hours using DIC. The curve exhibits a large range of strain, which is an advantage of the DIC. Also, the smoothness of the curve indicates a good stability of the measurement.

3.4. Measurement of Full-Field Deformation. Although standardized laboratory tests provide useful information of materials, direct real time measurements are also important to 


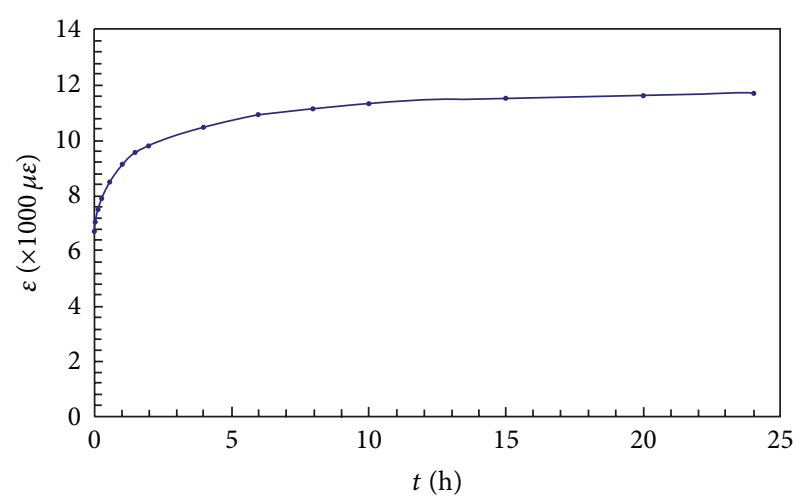

Figure 10: Creep law of K-PE material $\left(25 \mathrm{MPa}, 15^{\circ} \mathrm{C}\right)$.

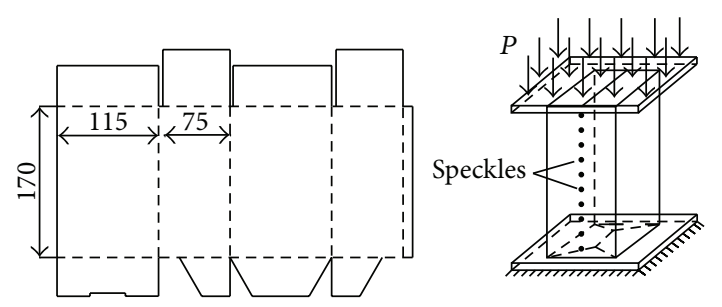

FIgURE 11: Box size and speckle arrangement.

assess the performance of the packaging during transportation. It will be more meaningful if full-field multipoint data can be acquired real time.

3.4.1. Materials and Methods. The test sample was a $0204 / 0215$ type corrugated box $(1.27 \mathrm{~mm} / \mathrm{F}$ flute $)$, with a dimension of $115 \mathrm{~mm} \times 75 \mathrm{~mm} \times 170 \mathrm{~mm}$. Ten speckles of a $15 \mathrm{~mm}$ interval were marked along the central axis of frontal surface with heights $1 \mathrm{~cm} \sim 16 \mathrm{~cm}$ from the bottom. Place the box on a solid base and apply a compressive load of total 20 25 $\mathrm{N}$ uniformly on the top of the box by an electronic universal testing machine (Figure 11). Use DIC to obtain the average strain $\varepsilon$ from each pair of adjacent speckles continuously.

3.4.2. Results and Discussion. Figure 12 shows the strains at the marked points along the central axis of the frontal surface. Since either the bottom or the top surface was not a solid panel, the frontal plane is subjected to both the compression and bending, leading to nonlinear strain curves. Since the bottom of the box is made up of four smaller pieces, its flexural rigidity is smaller than that of the top, so the the bending on the bottom is much larger than the top, and surface tensile stress of the side caused by bending is not a linear relationship with the top pressure and the height, as shown in the figure.

This experiment shows that DIC used only one set of instruments to obtain full-field multipoint data in real time without complex pretreatment such as surface spray and painting. The advantages of cost savings and high efficiency are shown again compared to other noncontact optical methods.

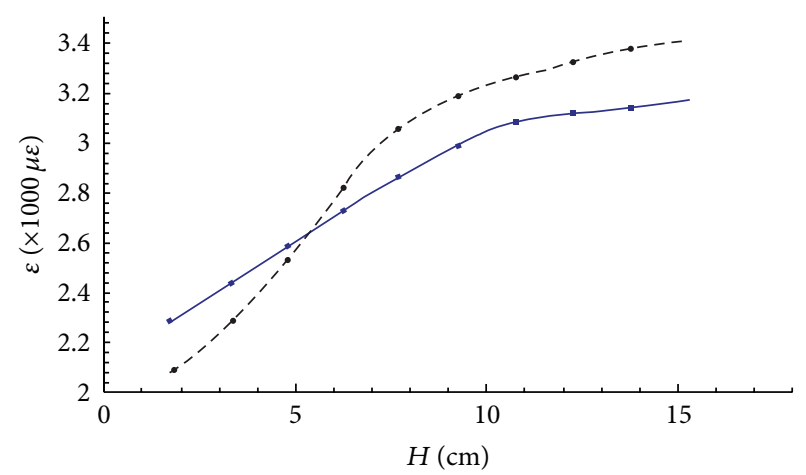

Figure 12: Compression strains at different heights.

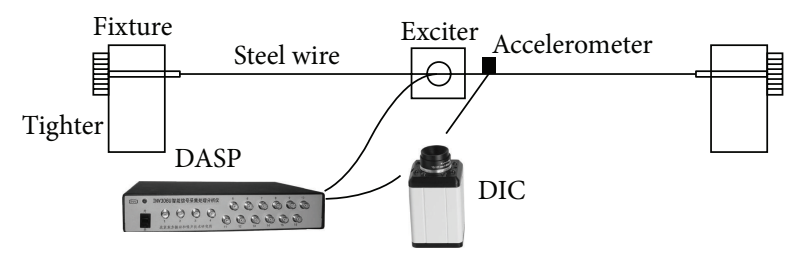

FiguRE 13: Vibration test.

3.5. Determination of Frequency. When packages are stacked outdoors, low-frequency vibration may take place due to wind or ground vibration [13-16]. Although it will not damage the packages, some sophisticated parts in the packages may be affected. To verify whether the DIC can be used in vibration test, we designed a vibration test of an excited tight wire.

3.5.1. Materials and Methods. A steel wire of a diameter of $0.1 \mathrm{~mm}$ was tightened by a tensioning device. On the wire, a piezoelectric accelerometer was installed, which was connected to a dynamic signal acquisition instrumentDASP. A vibration exciter was installed at the middle of the wire (Figure 13). The test consisted of the following steps:

(1) tight the wire;

(2) adjust CCD, use the connection point of the vibration exciter and wire as the speckle;

(3) on DASP, set low-pass filter at $100 \mathrm{~Hz}$ and set sampling frequency at $100 \mathrm{~Hz}$;

(4) turn on the vibration exciter;

(5) when the vibration signal was approximately periodic, use both the DASP and DIC to record the signal simultaneously;

(6) adjust the tightening force to change the natural frequency; repeat steps 4 and 5.

3.5.2. Results and Discussion. Table 1 lists the test results of the frequencies measured by the DIC and DASP. The results from DASP can be considered as the true frequencies. It can be seen that the results from DIC have errors less than $1 \%$, indicating a high accuracy. Two advantages of DIC are shown 
TABLE 1: Measured frequencies from DIC and DASP.

\begin{tabular}{|c|c|c|c|c|c|c|c|c|c|}
\hline \multirow{2}{*}{ No. } & \multicolumn{4}{|c|}{ DIC (Hz) } & \multicolumn{4}{|c|}{$\operatorname{DASP}(\mathrm{Hz})$} & \multirow{2}{*}{ Average error } \\
\hline & 1 & 2 & 3 & Average & 1 & 2 & 3 & Average & \\
\hline 1 & 6.0547 & 6.1707 & 6.1829 & 6.1361 & 6.1088 & 6.1073 & 6.1109 & 6.1090 & $0.444 \%$ \\
\hline 2 & 6.6772 & 6.7139 & 6.6528 & 6.6813 & 6.6942 & 6.6996 & 6.6983 & 6.6974 & $-0.240 \%$ \\
\hline 3 & 7.3975 & 7.3730 & 7.3975 & 7.3893 & 7.3547 & 7.3570 & 7.3564 & 7.3560 & $0.453 \%$ \\
\hline 4 & 8.1421 & 8.0994 & 8.1421 & 8.1279 & 8.1039 & 8.1032 & 8.1076 & 8.1049 & $0.283 \%$ \\
\hline 5 & 8.5815 & 8.4167 & 8.3740 & 8.4574 & 8.4452 & 8.4460 & 8.4451 & 8.4454 & $0.142 \%$ \\
\hline 6 & 9.7412 & 9.9182 & 9.9121 & 9.8572 & 9.9089 & 9.9074 & 9.9093 & 9.9085 & $-0.518 \%$ \\
\hline 7 & 10.6260 & 10.6630 & 10.6260 & 10.6383 & 10.5955 & 10.5962 & 10.5965 & 10.5961 & $0.399 \%$ \\
\hline 8 & 11.0900 & 11.3590 & 11.3340 & 11.2610 & 11.3689 & 11.3705 & 11.3707 & 11.3700 & $-0.959 \%$ \\
\hline 9 & 12.4940 & 12.4940 & 12.4940 & 12.4940 & 12.3817 & 12.4258 & 12.4414 & 12.4163 & $0.626 \%$ \\
\hline
\end{tabular}

TABLE 2: Comparison of DIC with conventional methods.

\begin{tabular}{|c|c|c|c|}
\hline Measurement & Features of DIC & \multicolumn{2}{|c|}{ Problems with conventional contact sensors (extensometers, strain gauges, etc.) } \\
\hline $\begin{array}{l}\text { Operation } \\
\text { mode }\end{array}$ & Noncontact & Contact & $\begin{array}{l}\text { Slippage } \\
\text { Difficulty in attachment } \\
\text { Specimen may damage the sensor due to fracture }\end{array}$ \\
\hline Object & $\begin{array}{l}\text { All material } \\
\text { Large dimensions }\end{array}$ & $\begin{array}{l}\text { Conventional } \\
\text { material }\end{array}$ & $\begin{array}{l}\text { Not applicable to special materials and small sample } \\
\text { Large samples require a lot of strain gauges }\end{array}$ \\
\hline Range & $\begin{array}{l}\text { Large range (several } \\
\text { millimeters to meters) }\end{array}$ & Fixed & Easily exceed the range \\
\hline Environment & $\begin{array}{l}\text { High temperature, humidity, } \\
\text { speed, and so forth }\end{array}$ & Normal & May not work in hostile environment \\
\hline Direction & $\begin{array}{l}\text { Any direction in plane, } \\
\text { simultaneous multipoint } \\
\text { measurement }\end{array}$ & Single & Need more strain gauges for different directions \\
\hline Parameter & $\begin{array}{l}\text { Displacement, distance, strain, } \\
\text { velocity, acceleration, } \\
\text { frequency, and so forth. }\end{array}$ & Single & Different instruments are needed for different parameters \\
\hline
\end{tabular}

again in the vibration test: noncontact and large distance up to a meter.

\section{Conclusion}

The experiments carried out in this study have shown that the DIC is an advanced and effective method to measure material mechanical properties, especially for flexible packaging materials. It combines two techniques: the digital image processing and recognition and optical measurement. The DIC has advantages of non-contact, no reinforcement effect, high precision over entire area, wide measurement range, and good measurement stability. With the development of technology in digital image processing and related areas, such as neural networks, fuzzy theory, pattern recognition, applications of the DIC will be more and more wide. For reference, a brief comparison of the DIC and conventional contact methods (CCM) is given in Table 2 .

\section{Acknowledgments}

This work has been supported financially by the National High Technology Research and Development Program of
China (2011AA100804), China Agriculture Science Technology Achievement Transformation Fund (2011GB2C200001), Ningbo Major Scientific and Technological Projects (2012C10028) and Talents Fund of Ningbo Institute of Technology, Zhejiang University (1149957G720).

\section{References}

[1] D. H. Xi, Z. L. Wang, D. Gao, and B. F. Song, "Several problems in packaging dynamics," Packaging Engineering, vol. 20, no. 3, pp. 2-5, 1993.

[2] A. S. Kobayashi, Handbook on Experimental Mechanics, Prentice-Hall, Upper Saddle River, NJ, USA, 1987.

[3] W. H. Peters and W. F. Ranson, "Digital imaging techniques in experimental stress analysis," Optical Engineering, vol. 21, no. 3, pp. 427-431, 1982.

[4] I. Yamaguchu, "Fringe formation in speckle photography," Journal of the Optical Society of America A, vol. 1, no. 1, pp. 81-86, 1984.

[5] P. Bing, Q. Kemao, X. Huimin, and A. Asundi, "Twodimensional digital image correlation for in-plane displacement and strain measurement: a review," Measurement Science and Technology, vol. 20, no. 6, pp. 1-17, 2009. 
[6] V. Tiwari, M. A. Sutton, and S. R. McNeill, "Assessment of high speed imaging systems for $2 \mathrm{D}$ and $3 \mathrm{D}$ deformation measurements: methodology development and validation," Experimental Mechanics, vol. 47, no. 4, pp. 561-579, 2007.

[7] V. Tiwari, M. A. Sutton, S. R. McNeill et al., "Application of 3D image correlation for full-field transient plate deformation measurements during blast loading," International Journal of Impact Engineering, vol. 36, no. 6, pp. 862-874, 2009.

[8] H. H. Gong, J. H. Jiang, and D. Q. Chen, "Displacement measurement by grid," Digital Image Correlation, vol. 15, no. 2, pp. 246-252, 2000.

[9] Y. L. Sun, S. X. Li, and J. Z. Li, "Investigation and modification of the digital speckle correlation method," Acta Photonica Sinica, vol. 30, no. 1, pp. 54-57, 2001.

[10] M. A. Sutton, J. Orteu, and H. Schreier, Image Correlation for Shape, Motion and Deformation Measurements, Springer, New York, NY, USA, 2009.

[11] Y. L. Wang and R. F. Sun, Packaging Auxiliary Materials, Hunan University Press, Changsha, China, 1988.

[12] ASTM D5083-2008, "Standard Test Method for Tensile Properties of Reinforced Thermosetting Plastics Using Straight-Sided Specimens".

[13] C. Bernad, A. Laspalas, D. González, J. L. Núñez, and F. Buil, "Transport vibration laboratory simulation: on the necessity of multiaxis testing," Packaging Technology and Science, vol. 24, no. 1, pp. 1-14, 2011.

[14] V. Rouillard, "Excitation techniques for resonance analysis of packages," Packaging Technology and Science, vol. 15, no. 5, pp. 267-274, 2002.

[15] J. Wang, Z.-W. Wang, L.-X. Lu, Y. Zhu, and Y.-G. Wang, "Three-dimensional shock spectrum of critical component for nonlinear packaging system," Shock and Vibration, vol. 18, no. 3, pp. 437-445, 2011.

[16] J. Wang, Z. W. Wang, F. Duan et al., "Dropping shock response of corrugated paperboard cushioning packaging system," Journal of Vibration and Control, vol. 19, pp. 336-340, 2013. 


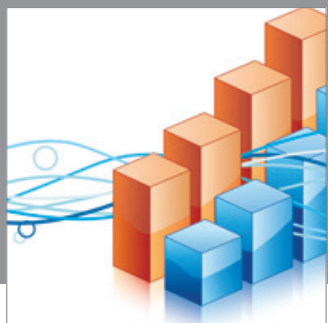

Advances in

Operations Research

mansans

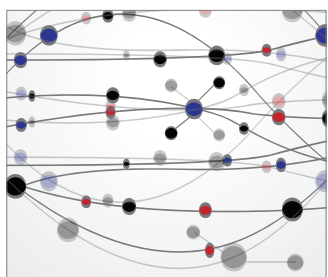

The Scientific World Journal
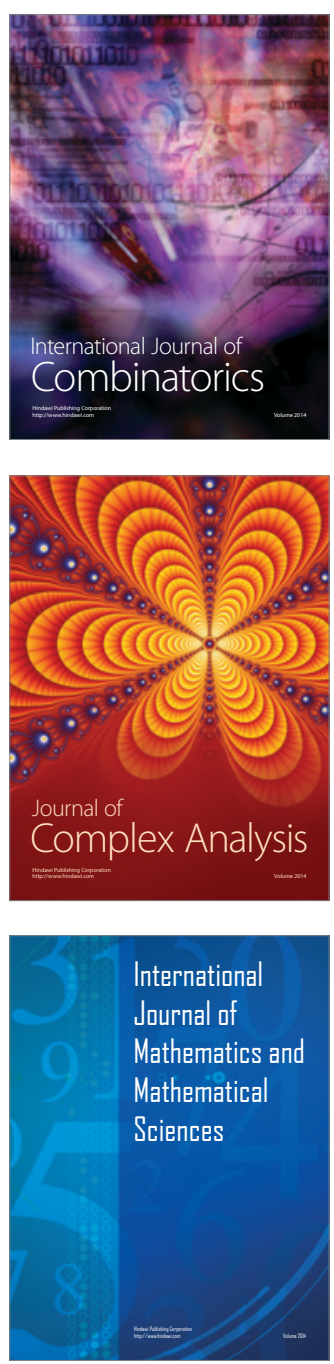
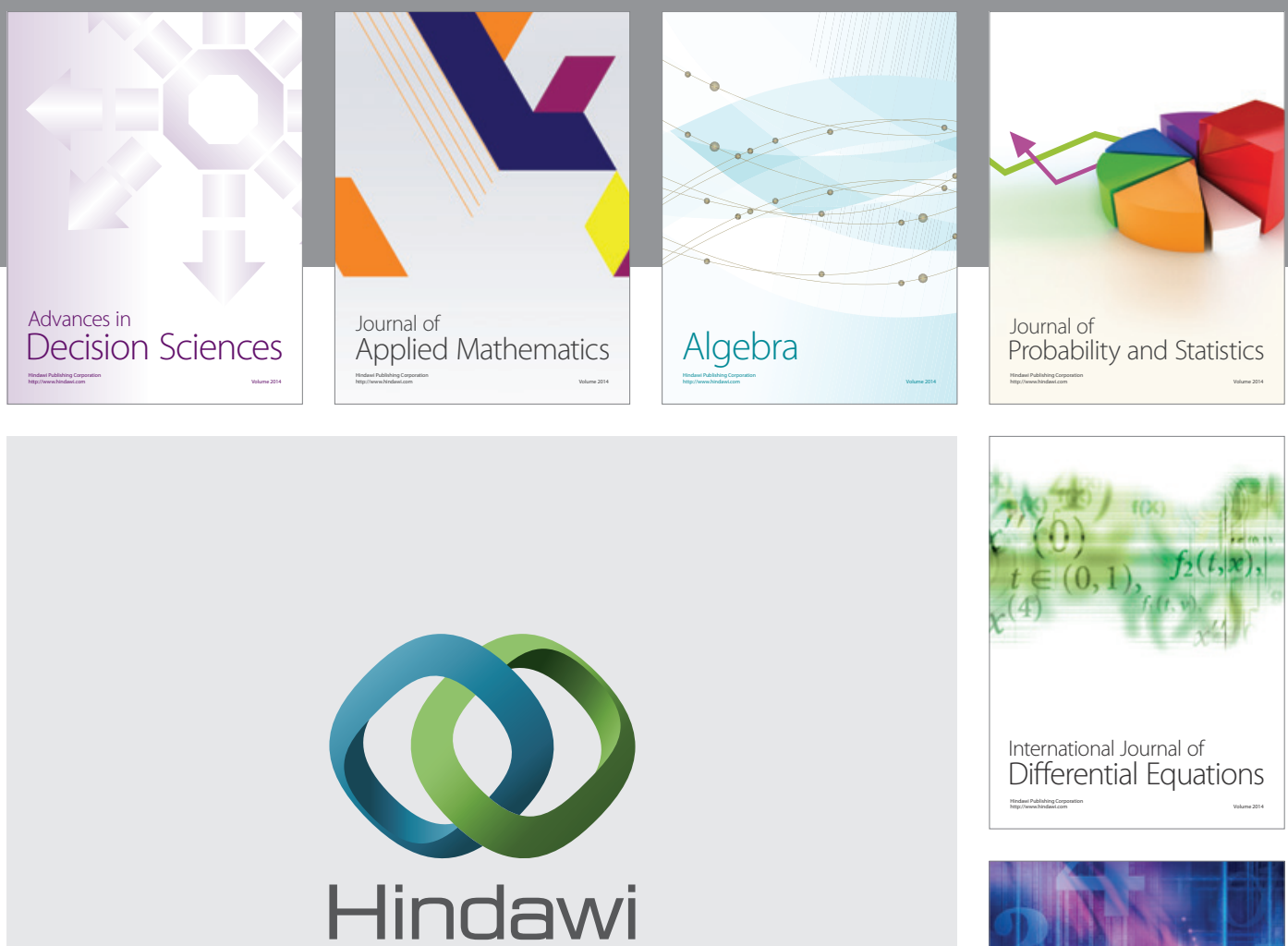

Submit your manuscripts at http://www.hindawi.com
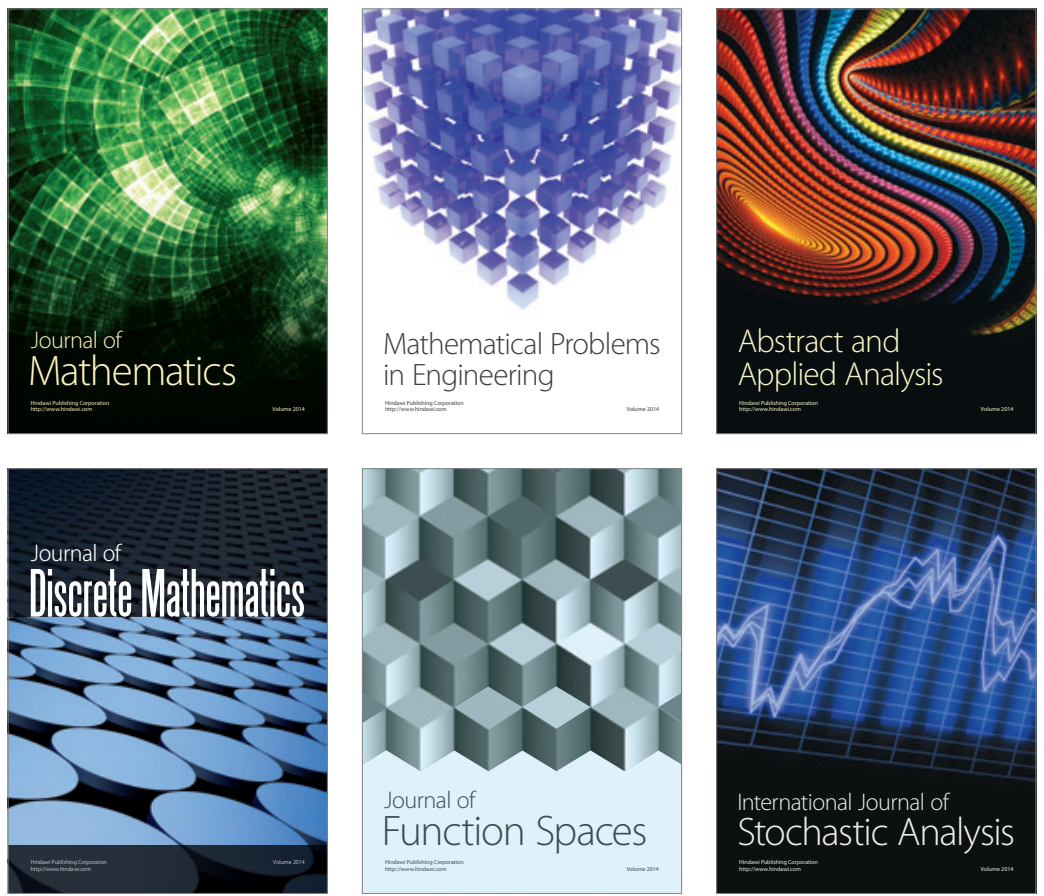

Journal of

Function Spaces

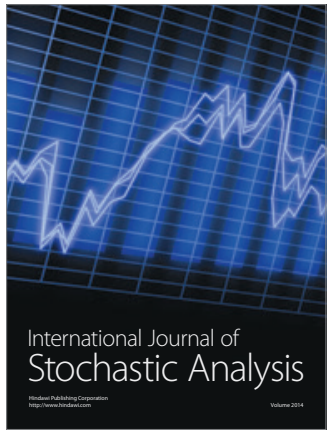

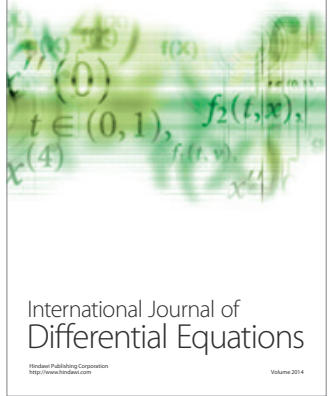
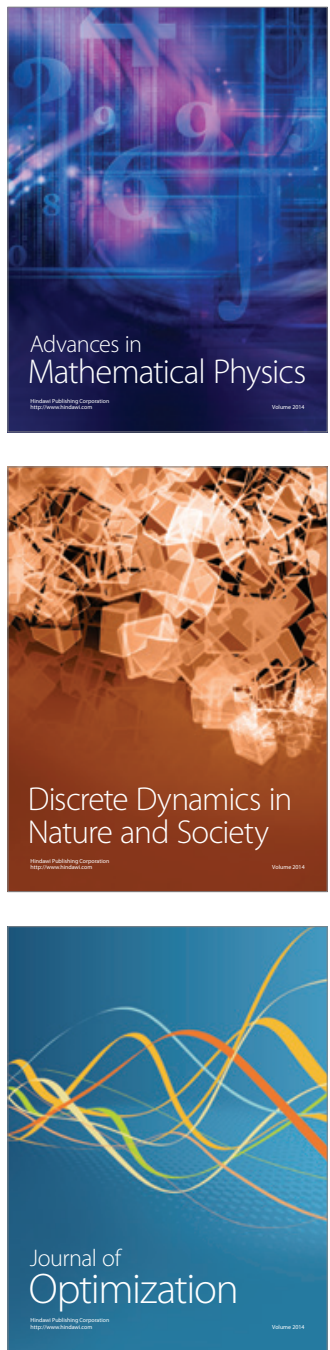